\title{
Fayalite Slag as Binder and Aggregate in Alkali-Activated Materials-Interfacial Transition Zone Study ${ }^{\dagger}$
}

\author{
Adeolu Adediran *, Juho Yliniemi and Mirja Illikainen \\ Fiber and Particle Engineering, University of Oulu, Pentti Kaiteran katu 1, 90014 Oulu, Finland; \\ juho.yliniemi@oulu.fi (J.Y.); mirja.illikainen@oulu.fi (M.I.) \\ * Correspondence: adeolu.adediran@oulu.fi \\ + Presented at the 1st International Conference on Smart Materials for Sustainable Construction-SMASCO \\ 2019, Luleå, Sweden, 10-12 December 2019.
}

Published: 18 November 2019

\begin{abstract}
Alkali-activated materials (AAMs) are an environmentally friendly option for Portland cement mortars and concretes. Many industrial residues such as blast furnace slag and coal fly ash have been extensively studied and applied as AAM precursors but much less focus has been on the use of fayalite slags. Water-cooled fayalite slag comes in granular form, which is then milled into fine powder (d50 10 microns) prior to its alkali activation. In addition, the un-milled granular fayalite slag can be used as an aggregate to replace sand in mortar. The alkaline solution utilized for the study was a mix of $10 \mathrm{M}$ sodium hydroxide solution and commercial potassium silicate solution. A liquid to solid ratio of 0.15 was held constant for all the mixes. The particle size distributions of the binder and the aggregates were optimized, and the microstructure and chemical composition of the interfacial transition zone (ITZ) was studied using scanning electron microscope coupled with energy dispersive $\mathrm{X}$-ray spectroscopy. ITZ is a region that exists between the aggregate and the binder and this can influence the mechanical and transport properties of the construction materials. The results showed that the mechanical properties of mortar having fayalite slag as aggregate and binder was significantly higher than one with standard sand as aggregate. No distinct ITZ was found in the samples with fayalite slag as aggregate. The outer rim of the fayalite slag aggregate participated in the hardening reaction and this significantly contributed to the bonding and microstructural properties of the mortar samples. In contrast, an ITZ was observed in mortar samples with standard sand aggregates, which contributed to its lower strength.
\end{abstract}

Keywords: Fayalite slag; aggregate; binder; alkali activation; interfacial transition zone

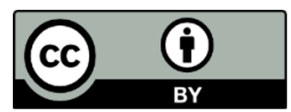

(C) 2019 by the authors. Licensee MDPI, Basel, Switzerland. This article is an open access article distributed under the terms and conditions of the Creative Commons Attribution (CC BY) license (http://creativecommons.org/licenses/by/4.0/). 